[Hall, C., Morris Matthews, K., \& Sawicka, T. (2004). PerformanceBased Research Fund (PBRF): Policy and Practice. New Zealand Annual Review of Education, 13, 79-104]

\section{Performance-Based Research Fund (PBRF): Policy and Practice}

\author{
CEDRIC HALL, KAy MORRIS MATTHEWS AND \\ THERESA SAWICKA
}

\section{Abstract:}

This article examines the first cycle of the PBRF exercise. It critiques the policy and describes the system used to reach judgements about the respective research performance of tertiary institutions. It includes a description of one institution's response to the system, including the provisions introduced to obtain formative benefit out of what is essentially a summative evaluation process. The article comments on some of the issues that underpin the system, such as the workload and stress for staff in institutions, the potential negative impact on teaching, the harmful effects of classifying new researchers as "research inactive", and the high compliance costs for institutions in operating the system. It also questions the absence of any real long-term analysis of the benefits of the PBRF. However, despite these criticisms, the conclusion is reached that the PBRF has been carefully desioned and includes many features which reflect well on the validity and reliability of the information provided.

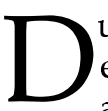

uring the 2003 academic year, over 6000 academics employed in eight universities, two polytechnics, four colleges of education and one wananga submitted for the first time a portfolio of their research outputs covering the previous six years. The exercise, known as the Performance-Based Research Fund (PBRF), was compulsory, time-consuming, and for many participants, very stressful. Never before had academics in New Zealand been assessed in this way for their research productivity. The process involved the use of internal institutional assessment panels, followed by national assessment panels, made up of subject area peers, to assign a grade to the portfolio of each academic. The future significance of the PBRF for tertiary institutions in New Zealand is that the quality of grades from portfolios will in future be directly linked to the amount of research funding that the government allocates to each tertiary institution.

This article presents the first analysis of the PBRF, written from the perspective of three senior staff involved in the administrative and assessment process at Victoria University of Wellington. The material presented covers the background to the policy, along with a brief commentary on some of its implications. This is followed by a detailed description of the PBRF portfolio requirements, including an analysis of the operation as a quality assurance mechanism. The article then describes the ways in which Victoria University responded to the process, and gives a summary of the results of the exercise, along with a discussion of some of the issues arising.

\section{The Policy and Commentary}

Origins of the PBRF

Tertiary education institutions (TEIs) and private training providers (PTEs) in New Zealand are currently funded on the basis of how many equivalent full-time students (efts) enrol each year. Under a new framework the government will from 2004 fund tertiary institutions based upon new sets of criteria monitored by a newly established Crown entity, the Tertiary Education Commission (TEC). This body had its origins in the Tertiary Education Advisory Commission (TEAC) set up in April 2000, "to devise a long-term strategic direction for the tertiary education system" (TEAC, 2001, p. 4). The result, commonly referred to as the Tertiary Strategy, "is to make New Zealand a world-leading knowledge society by providing all New Zealanders with opportunities for lifelong learning" (TEAC, 2001, p. 4).

Such opportunities are linked to the ways that students can access tertiary education, and once there, be assured of high quality teaching and research. What the Commission identified included: barriers to access, such as the rising debt accrued through the Student Loans Scheme and inadequate learning support for Maori and Pacific students; financial difficulties for institutions because of fluctuations in student numbers; and problems associated with recruitment and retention of high-quality academic staff and post-graduate students. Another concern the Commission highlighted was the existence of a separate system operated by Skill New Zealand that purchased industry training, youth training and training opportunities. This too 
did not seem to be working efficiently, was too costly, not sufficiently transparent and placed over-rigid limits on student places.

The Commission decided that a system was needed that did away with the separate sector approach and "encouraged seamless learning or equity for learners" (TEAC, 2001, p. 6). One way of achieving this was to apply the same rules across the tertiary sector and, most importantly, to monitor those rules so that all providers of tertiary education could be held accountable in the same way for government funding received.

Central to this goal is a new unified funding framework for tertiary institutions. In summary, this means that all tertiary institutions will be monitored, audited and required to comply with rules and regulations that go with eligibility for state funding. Charters and Profiles will be required to make available to the publicinformation on such things as: student access; retention and quality of completed qualifications; as well as costs and categories of different academic programmes. In addition, government funding for teaching and research will be separated out, and money for research will be allocated based upon the quality of research generated by each institution measured on a performance-based system. The latter will be done in two ways: through the Performance-Based Research Fund and by way of funding to Centres of Research Excellence (the latter is already in place). To address the anomalies in the infrastructures of tertiary institutions, a Strategic Development Fund (SDF) will reward innovation and management. To address equity issues, policies surrounding student financial support will be reviewed, and tertiary institutions will be required to put in place specific measures to support the learning of Maori and Pacific students. The Tertiary Education Commission (TEC) will be responsible for the oversight and audit of the Tertiary Framework (TEAC, 2001).

\section{What the policy means}

For institutions to qualify for research funding under the PBRF scheme, individual academics have to account for completed research within a given time period, and departments/schools must report on the completion rates of their post-graduate research students. This means that the ranking of academics for their portfolios, the number of completed post-graduate students, and the total amount of money academics bring into the institution from research grants, all combine to provide the basis on which each tertiary institution will be allocated a research funding entitlement. In December 2003, TEC estimated "that the fund would eventually have more than $\$ 134$ million to allocate and some $60 \%$ of that would be allocated on the basis of panel assessment of portfolios" (New Zealand Vice-Chancellors' Committee, 2003, p. 2).

Whilst having a research component built into the ways tertiary institutions are funded, instead of employing an exclusively efts-funded model, is a fairer method of allocating funding, the PBRF policy component is (by mid-2004) impacting on the way academics work and tertiary institutions operate. For the colleges of education, PTEs and wananga, this impact appears to be greatest. Such institutions have traditionally emphasised teaching rather than research. On an efts-based funding formula, most of these institutions, especially the wananga (which charge minimal fees), do very well. However, at the same time, the demonstration of accountability for the money received has proved increasingly difficult. This has been highlighted by the collapse of a large PTE Language School in 2003. Generally, the new Tertiary Education Strategy, with its compulsory charter profile requirements and increased accountability for funds received, will go some way to address inadequate management. For non-university tertiary institutions, however, the efts-based funding alone may not be sufficient to meet their needs. The policy quite deliberately makes clear that all tertiary institutions need to be "research active" to qualify for additional funding. It seems that there will be inevitable consequences flowing from this. The most likely of these is linked to the government objective to consolidate the number of tertiary institutions overall, especially those offering professional qualifications. In requiring research outputs from such institutions, considerable change will be forced. In some cases, notably the colleges of education and the polytechnics, this could mean amalgamation with other institutions or, in the case of some PTEs, closure because of inadequate funding.

For those tertiary institutions better able and equipped to cope with the PBRF (such as the main universities), the new funding formula risks generating increasing competition. This is unfortunate, given the small size of the possible student population and amount of funding to be allocated. While the funding available to the Centres for Research Excellence may encourage cross-university co-operation, such as with the Maori research grouping currently, there is another 
disturbing development afoot. At departmental and school levels, staff recruited to a university are now more generally favoured in line with the number of recent high-quality publications they bring with them. In addition, one large university has already strategically recruited established senior academics from overseas, with their inevitably topranking portfolios. This represents a form of "game-playing" which has questionable benefits for the long term development of New Zealand's research capability. Continuity requires employment and encouragement of young academics who are in the process of establishing their credentials - those who will become the next generation of high profile researchers.

The implications for the average, and particularly the below average, academic researcher is that there is now added pressure to produce quality research outputs within a relatively short time period. Academics will need mentoring and support in order to achieve a "research active" (or higher) category in order to be eligible for consideration in a PBRF world. While this is not unreasonable for new academics, such pressure may result in the loss of mid- or late-career staff, some with high teaching loads, at a time when there is little funding to replace positions. The result would be added pressure in teaching an academic programme on those who remain, as well as less time for research. There is already evidence of "research inactive staff" taking on more teaching to release the "research stars" from this activity, so as to achieve a better PBRF result for the institution.

However, promotion policies within universities tend not to reward teaching to the same extent as research, and thus a two-tiered system of recognition is fostered. The particular difficulty with this development is that it runs counter to a system that favours better links between research and teaching. In the PBRF world, the only way this can be achieved is if the majority of staff are both research active (achieve a high PBRF grade) and contribute significantly to an institution's teaching profile. The PBRF policy, instead of fostering the government's goal of greater cooperation between universities, has the potential to increase levels of individual work-place stress, as well as competition between colleagues, departments/schools and institutions. Indeed, far from solving current issues in recruitment and retention, the new funding framework will likely add fuel to "inter-New Zealand institution head-hunting" by those that are larger and can offer better than average salary packages.

\section{Design of the PBRF}

\section{The development of the PBRF system}

A key development in the establishment of the PBRF was a discussion document for stakeholders released in September 2002 (PBRF Working Group, 2002). The document was prepared by a Working Group appointed by the Government and comprised representatives from most universities as well as other stakeholder groups. The significance of this document is that it laid the groundwork for the system that was eventually instituted (with some modifications).

The Working Group also recommended the establishment of a peer review process based on panels in different subject areas (initially 11 but later increased to 12) rather than a process based simply on performance measures. This was seen as important for judging the actual quality of research outputs, rather than using proxies for quality such as citation indices. The group also provided four options for "scoring" the research output of academics and identified a transitional period for phasing in the PBRF system.

The publication of the final Working Group report by the Transition Tertiary Education Commission and the Ministry of Education (2002) signalled the next stage of the process. The model developed by the Working Group provided the basis for a period of implementation during which key components of the system were instituted along with a timetable (periodically updated) for completing each phase of the process. Throughout the process, TEC released a number of implementation updates (mostly at one month intervals throughout 2003) which kept stakeholders informed of the developing process and, from time to time, invited feedback on particular aspects of the system.

Comprehensive details of the system were contained in a Guide published by TEC in May. The Guide was updated and re-released in July 2003 (TEC, 2003). This document set out:

- aims and guiding principles of the PBRF;

- the key elements of the system;

- participation criteria for researchers;

- the process for calculating research degree completions by TEIs;

- the process for TEIs to follow in submitting external research income information along with the criteria for what should and should not be included; 
- guidance for TEIs and their staff on preparing evidence portfolios;

- the process for assessing, scoring and assigning a "quality category" (grade) to evidence portfolios, along with details of the moderation procedure;

- the reporting framework.

Brief details of each of these are given in the following paragraphs.

Aims and guiding principles

The main aims of the PBRF are to:

1 Increase the average quality of research;

2 Ensure that research continues to support degree and postgraduate teaching;

3 Improve the quality of public information on research output;

4 Prevent undue concentration of funding that would undermine research support for all degrees or prevent access to the system by new researchers; and

5 Underpin the existing research strength in the tertiary education sector. (TEC, 2003, p. 5)

A number of guiding principles (ten in all) were also adopted to ensure that the system was introduced in line with the intentions (TEC, 2003, p. 7). The principles focus on notions such as "comprehensiveness" (the system should cover the full range of research/investigative activities), "respect for academic traditions" (academic freedom should be respected), "differentiation" (stakeholders and governments should be able to discriminate between TEIs on the basis of their research quality), and "cultural inclusiveness" (the system should reflect New Zealand's bicultural nature).

\section{Key elements of the system}

The key elements of the system and their weightings for future funding were:

- the peer assessment of evidence portfolios submitted by eligible staff of TEIs $(60 \%)$;

- research degree completions of each TEI (25\%); and

- external income generated by each TEI $(15 \%)$.

\section{Participation (eligibility) criteria of TEI staff}

The criteria adopted for those who would be required to submit an "evidence portfolio" comprised: staff employed on 31 July, 2003, in a $0.2 \mathrm{fte}$ position or more, on a contract for at least one year, and whose duties included research and/or degree level teaching.

\section{Research degree completions}

The procedure for supplying information on research degree completions requires all TEIs to submit data annually (a single return) based on a weighted rolling formula. The formula gives $50 \%$ weighting to the last year of the preceding three year cycle, $35 \%$ for the second year of that cycle, and 15\% for the first year of that cycle. However, for the first round of the PBRF only 2002 data were included - the rolling formula will be phased in over the next two years.

\section{External research income}

The procedure for external research income uses the same rolling formula as that for degree completions $(50 \%, 35 \%$ and $15 \%$ respectively for the most recent years of a three-year rolling cycle). It also uses the 2002 figure supplied by TEIs for the first PBRF exercise.

\section{Guidance for TEIs and their staff in preparing evidence portfolios}

Guidance for staff preparing their evidence portfolios focused, in particular, on the components of a portfolio along with advice on how to complete each component. The components comprise: Research Outputs (70\%); evidence of Peer Esteem (15\%); and evidence of Contribution to the Research Environment (15\%). As part of the evidence under research outputs, each staff member was required to nominate his/her four most important or significant contributions and include a brief description of why they were chosen. Staff were also asked to list up to 50 further outputs from the period 1997-2002 under various headings that corresponded to different categories of research or its equivalent (e.g., artistic artefact in the area of design). General guidelines on the acceptability of different outputs for inclusion in the portfolios of academics were provided by TEC and more specific guidelines were provided by the evaluation panels for each area. Similarly, guidelines on what constituted evidence of "peer esteem" (e.g., membership of the editorial board of an international journal) and "contribution to the research environment" (e.g., number of research students supervised to completion) were also provided. 
Table 1 Abridged Criteria* for Assessing Evidence Portfolios: Research Outputs

\begin{tabular}{|c|c|}
\hline Score & Abridged Descriptions \\
\hline & $\begin{array}{l}\text { Descriptive Overview } \\
\text { Staff members will present up to four of their "best" research } \\
\text { outputs. All nominated outputs must be peer-reviewable. Outputs } \\
\text { include printed academic work, published and unpublished work, } \\
\text { work published in non-print media, and other forms of outputs } \\
\text { such as patents, materials products, performances and exhibits. } \\
\text { Portfolios may include research primarily concerned with } \\
\text { methodological, theoretical and analytical issues (basic or strategic } \\
\text { research), and/or applied research primarily directed to and } \\
\text { impacting on practices, technologies or policies. }\end{array}$ \\
\hline
\end{tabular}

7

6 The portfolio would be expected to demonstrate leadership and accomplishment in research exemplified by a platform of world class research that includes highly original work that ranks with the best of its kind. The portfolio would be characterised by outputs that represent intellectual or creative advances, or contributions to the formation of new paradigms, or generation of novel conceptual or theoretical analysis and/or theories or important new findings with wider implications.

5

4 The portfolio demonstrates a platform of significant research output that has generated substantial new ideas, interpretations or critical findings and makes a valuable contribution to existing paradigms and practices. The research outputs are well researched and technically sound. The portfolio typically includes outputs that are presented in reputable channels considered to be at least at a middle level of excellence.

2 The portfolio demonstrates a platform of research activity (or developing activity) and output that is based on a sound/justifiable methodology, and makes a contribution to research within the discipline and/or to applied knowledge.

1 Minimal evidence of research outputs.

0 No evidence of research outputs.

( ${ }^{*}$ Abridged from TEC, 2003, pp. 196-197)
Assessing, scoring and assigning a "quality category"

The procedure for assigning grades to each portfolio involved the use of both internal and external assessment. TEIs were required to provide an internal assessment of each portfolio in line with the grading criteria contained in the TEC Guidelines (2003). (The grading procedure is summarised shortly.) It was recommended that TEIs adopt procedures which mirrored, as far as possible, the procedures for grading used by the TEC appointed panels. Once the TEI had completed its assessment, all portfolios were sent to TEC for panel evaluation. The processes employed by TEC included a check on the validity of data in each portfolio. Following this check, panels met to assign/confirm the grade awarded to each portfolio. This was followed by a moderation procedure designed to ensure comparability of assessments across panels.

The system used to score and grade portfolios made use of a $0-7$ scale, with " 7 " corresponding to performance of the highest international standing and " 0 " indicating that no evidence had been provided in the portfolio for that component. Table 1 sets out the scale in more detail and provides an abbreviated description of the criteria used to score research outputs (abridged from TEC, 2003, pp. 196-197). Similar statements were provided by TEC for both peer esteem and contribution to the research environment.

Table 2 Portfolio Evaluation for Dr B. Grade

\begin{tabular}{|l|c|c|c|}
\hline \multicolumn{1}{|c|}{ Category } & $\begin{array}{c}\text { Weighting } \\
\text { (W) }\end{array}$ & $\begin{array}{c}\text { Score } \\
(\mathbf{R})\end{array}$ & $\mathbf{W} \times \mathbf{R}$ \\
\hline Research Output & $70 \%$ & 4 & 280 \\
\hline Peer Esteem & $15 \%$ & 6 & 90 \\
\hline Contribution to Research Environment & $15 \%$ & 5 & 75 \\
\hline & & Total Score & $\mathbf{4 4 5}$ \\
\hline
\end{tabular}

The conversion of ratings for each of the three components into an overall score for a portfolio is illustrated in Table 2 . In the example shown, the final score of 445 is obtained by multiplying the weighting of each component $(\mathrm{W})$ by the rating $(\mathrm{R})$ awarded and then summing up the products for each of the three components. Portfolios which 
scored 600 + were graded " $A$ ", those between 400-599 were graded "B", those between 200-399 were graded " $C$ ", and those less than 200 were graded " $\mathrm{R}$ " (initially labelled as "research inactive").

\section{The reporting framework}

The reporting framework for the PBRF (TEC, 2003, pp. 226-238) sets out both the purpose of reporting and 11 principles governing the reporting process. Details of the actual process are also provided. The purpose of the reporting framework includes the statement:

The reporting framework will ensure public access to a wide range of information relating to research performance and activities of the participating TEOs. This is expected toenhance accountability (both at the institutional and sub-institutional levels) and improve the capacity of relevant stakeholders in the tertiary education sector (including students, prospective students, research funders, providers, the government and business) to make informed decisions. (TEC, 2003, p. 227)

The principles underpinning the reporting of results include the need to maintain confidentiality of a staff member's quality grade, the minimisation of "game-playing" by TEIs (see earlier comments), the opportunity to facilitate benchmarking amongst TEIs, and the maintenance of cooperation of academic staff. It should be noted that the first and last of these has already been the subject of a dispute involving the Association of University Staff (AUS). The essential point of debate here was the release to universities of each person's grade, and the potential for this information to be used in ways that were not consistent with the purposes for which the data were originally collected. At Victoria University, for example, the AUS disputed the proposal of the University to award " $A$ " and " $B$ " grade academics a bonus payment. This proposal has subsequently been withdrawn.

The final section of this article provides brief comments on some of the issues related to the report's findings.

\section{PBRF as a quality assurance mechanism}

Over the past 10-15 years, tertiary institutions have increasingly been subjected to external quality monitoring of various kinds. This includes processes for accreditation and/or programme approval (e.g., by the New Zealand Qualifications Authority or New Zealand ViceChancellors' Committee), external academic (quality) audit, and various other reviews either imposed by the Government or self-initiated, leading to outcomes such as restructuring or mergers or even closure. Some organisations have engaged in quality monitoring through ISO or other systems of specifying standards, while others have developed benchmarking strategies to "lift their game" in relation to standards or targets based on the performance of their benchmarking partners.

A key distinction in the literature on different approaches to quality monitoring is that between "accountability" (e.g., compliance with requirements) and "improvement". For example, bench-marking in its true spirit is an activity which is voluntarily undertaken (or initiated) by an organisation with the express purpose of working with partners to define and achieve higher standards of performance. It is principally a quality "improvement" mechanism. Quality (academic) audit, on the other hand, emphasises both "accountability" and "improvement" although supporters of this approach like to stress the latter. Quality audit operates by investigating whether the quality assurance and control mechanisms of an institution are meeting their purposes. This process does not judge or measure quality per se, but seeks to ascertain whether the systems being operated by an organisation are achieving their stated goals. In this sense it is an "accountability" mechanism. However, quality audit also seeks to prod an institution into self-evaluation and improvement, the belief being that the hallmark of a "quality" organisation is its ability to self-assess its own strengths and weaknesses and take corrective action.

The PBRF falls under a different category of quality monitoring, known as "quality assessment". Whereas quality audit focuses on whether an organisation has effective systems for monitoring its activities, quality assessment directly attempts to gauge or measure the effectiveness of an institution (or a unit within it) to determine how well it is performing. It is generally considered to be a more "hard-edged" approach to quality monitoring than quality audit, but its dangers need also to be understood.

First, because quality assessment relies upon measurement, it often has the effect of focusing only on those things that are easily measured. It would be fair to say, however, that the PBRF has given some attention to this problem in its attempt to place as much emphasis on research impact as research quantity. 
Secondly, quality assessment is very much a "summative" device - it is strongly "accountability" oriented and provokes improvement more by "stick" than "carrot". To become a "formative" device, quality assessment usually needs to be supplemented by additional processes which promote quality improvement as a goal. The next section of this paper looks at how Victoria University has responded to the PBRF process in order to add a formative focus to the process.

Thirdly, quality assessment tends to provoke competition in ways that are not always positive for overall system improvement. For example, if a limited pool of funding is available, organisations which might otherwise have cooperated to achieve educational or research goals may now act in opposition, to ensure that they remain competitive for achieving a greater share of the funding pool. If a particular government goal is likely to be best achieved by cooperation rather than competition, a good deal of thought needs to go into the design of a quality assessment process to ensure that the negative consequences of the system are recognised and guarded against. In respect of the PBRF, an evaluation of the extent to which the system creates unproductive competition and game-playing by institutions needs to be undertaken.

\section{Victoria University of Wellington's Response}

\section{The internal process}

The PBRF quality evaluation of the TEI's research performance required every eligible academic staff member to produce an Evidence Portfolio (EP) of their research over the previous six years. As indicated earlier, eligibility was determined by their status as an academic staff member (holding at least a 0.2 position) and the expectation that they were engaged in research and involved in degree-level teaching. The evaluation process was a two-step procedure, involving an internal and an external process. This section focuses on Victoria University's internal process.

The data to be collected from each staff member were described in an earlier section of this paper. To standardise the EP format the TEC agreed to develop and distribute software for the submission of EPs to the TEIs by the end of May 2003. The deadline for the submission of the EPs with their quality categories (grades) from the TEI's internal processes was the end of September 2003. During this period the TEC was still consulting with TEIs and finalising the details of the required data and its submission process. Thus the TEIs were given four months to:

- create a census of eligible staff;

- distribute TEC software to each eligible staff member;

- support academic staff in producing EPs according to the prescribed format;

- convene the internal panels;

- evaluate the portfolios;

- convene a moderation panel to calibrate the work of the panels and check the comparability of grades;

- hear any appeals;

- prepare a complete collection of the four nominated research outputs from all EPs;

- finalise the grades and submit the EPs to the TEC for the external process to begin.

Many of those in the tertiary sector who were asked to organise the collection of this information regarded the deadline as virtually impossible to meet and asked that the implementation be put off for a year. This was not agreed to and the tight deadline doubtless added to the pressure in the decision-making process for all parties concerned. There was a sense for those involved in implementation that the ground rules were constantly shifting and this continued to the end of the process. The final guidelines for the evaluation were made available in July, two months before the deadline.

At Victoria University the implementation of the PBRF evaluation was the responsibility of the Pro Vice-Chancellor (Research) and the Research Office (a manager and two administrators). In other TEIs there was a different mix of administrative units taking on these responsibilities. Each TEI had therefore a slightly different orientation towards the significance of the data collected, their method of collection, and ways of dealing with the impact on academic staff. At Victoria University there was no expertise or any data collection system within the Research Office to create the records for EPs, other than that provided by the TEC. The decision to rely on the TEC software, despite the perceived risk about the delivery date, meant that Research Office staff focussed their attention on the process of implementing the evaluation and on the support of academics in creating their EPs. The 
primary goal was the production of valid portfolios for all eligible staff Getting information out to staff was the first step. A series of university-wide staff forums were organised to brief people about what was to come. The flow of information was kept up through a weekly column under the hand of the PVC(Res) in VicNews (a university newsletter). As draft information was still being sent out from TEC, all information was still in a provisional form. However it meant that staff did not have to read these draft documents themselves in order to understand what was to come.

At the same time, School Advisory Groups (made up of senior colleagues in each university school) were set up to help staff prepare their EPs. The convenors of these groups were called together to be briefed by the PVC(Res). A mocked-up document based on what was known of the EP format was created in Microsoft Word and this was distributed to all academic staff so that a draft EP could be prepared for review.

Where this process was embraced, colleagues mentored and coached one another to improve their EPs in terms of the choices they made about inclusion, e.g., in the four nominated research outputs. Thus even before the EP software finally arrived, draft versions of the EPs were being circulated amongst colleagues for comment.

The process of refining drafts continued even after the software arrived at the end of May. To manage the versions of EPs, a set of shared folders was set up for each school. Schools had a designated administrator who managed the progress of the EPs through a system of folders and a tracking spreadsheet. Portfolios were produced in schools with the help of colleagues. However the disciplinary composition of the panels was specified by TEC, and did not always match the university's school structure. A process had to be put in place to manage the electronic passage of EPs from staff to the appropriate internal panels and back again.

The internal panels had their own conveners who were largely the Associate Deans (Research) in each faculty. Internal panel members also had their own briefing from the PVC(Res) concerning the evaluation of EPs. At times, it was possible to base the briefings on final TEC documents, but not always. Because the design was being finalised at the time TEIs were implementing the PBRF in their institutions, there was always a sense of uncertainty and a feeling that the rules were constantly being changed. When the final guidelines were released on 25 July 2003, it was almost too late to accommodate all the details for Victoria University's internal panel process.

At the end of May, when the software finally arrived, it was distributed to all academic staff on their own desktops. Alternative arrangements were sought for Macintosh users, as the software did not work on these computers (a significant impediment to the distribution of the software across the tertiary sector). Portfolios were completed and sent to the Internal Panels for evaluation. The Victoria University deadline set for the completion of the evaluation process was the end of July. Once the quality categories had been decided, the results had to be moderated by a panel made up of the subject panel chairs and convened by the PVC(Res). At that stage there were still a few EPs to be completed, but by the time the moderation process began there was one hundred percent submission of portfolios.

The deadline for the completion of the moderation process was mid-August. After this, a letter containing the grades and score composition for each part of the portfolio was sent to each staff member from the Research Office, giving staff two weeks to appeal the result. The release of the score was carefully considered, after much deliberation in project team meetings. It was felt that this was the only way that staff members could understand their grades. Heads of School were also notified of the grade distribution in their school. As one of the purposes of the PBRF evaluation exercise is to improve the average quality of research in New Zealand TEIs, Victoria University took the view that its Heads of School needed to know how well staff in their schools were performing, in order to plan for the future and provide mentoring support. Heads of School also acted as advocates for their staff where a quality category appeared anomalous in terms of their knowledge of the person's performance.

The appeals process took longer than anticipated, as opinions had to be sought elsewhere in some cases. Finally, 536 EPs were sent to TEC.

\section{Incorporating a formative dimension}

For those implementing the collection of the data for the EPs in their institutions there were two important issues: the collection of highly detailed data in the specific format required and the impossibly short amount of time in which to do it. Under the leadership of the PVC(Res), Victoria University focussed its efforts in the Research 
Office, hoping that despite the considerable compliance costs involved in the data collection, it would consolidate research information for its own benefit within the structure of the Research Office and the University's Research Committee (URC). The university already had in place its own research evaluation policy and process, implemented by the URC, the first round having been completed in 1998. The second round was put on hold in 2001 in anticipation of the PBRF evaluation. The channelling of all the information through the research management infrastructure was seen as a key component to retrieving some benefit for the institution from the staggering compliance costs of the exercise. It was used to gain first-hand experience of the university's research strengths and weaknesses, areas where research support was lacking, and potential strategies for improving performance even before the results from TEC were received. For example, initiatives put in place before the end of 2003 included the creation of a sub-committee of the URC to focus on staff development in the area of research, an appointments process for a coordinator who would focus on professional development in research, and targeted small grants for new researchers. In addition, schools are now in the process of deciding how best to use PBRF funds so as to advance the quality of research undertaken, as well as to enhance opportunities for new researchers. These initiatives, along with the positive manner in which Victoria University communicated and supported its staff through the process, illustrate ways in which the university has added a significant formative dimension to what was largely a summative exercise.

\section{Results and Issues}

\section{Release of the PBRF report}

The PBRF report (Tertiary Education Commission, 2004) was finally released in late April, 2004 but not without first undergoing a major challenge. The report was delayed for a month pending the outcome of a High Court action brought by Victoria and Auckland Universities concerning a section of the report which provided international comparisons between New Zealand and British universities. Two major issues of concern were raised: first, that the international comparison was not contemplated as part of the PBRF process, and did not come to the attention of the Vice-Chancellors until early March
2004 (just prior to the intended release of the final report); secondly, that such a comparison was invalid because of fundamental differences between the British Research Assessment Exercise (RAE) and the PBRF. The view was that such a comparison was unfairly damaging to New Zealand universities and would impact negatively on their position in the international market. The court upheld the action of the universities. This resulted in the relevant sections being deleted from the report.

\section{Main findings}

The final report comprises nine chapters and nine appendices. These set out the background, aims, procedures and interpretation framework (chapters 1-4); the results for the three components of the system (chapters 5-7); and the apportionment of funding and the way forward (chapters 8-9). The appendices provide further information and a more detailed statistical analysis. The following paragraphs provide a very short summary of the key findings.

Table 3 Example of aggregation of EP grades for a fictitious unit

\begin{tabular}{|c|c|c|}
\hline EP Grade and Weighting $(\mathbf{W})$ & Number of Staff $(\mathbf{N})$ & Calculation $\mathbf{( W \times \mathbf { N } )}$ \\
\hline $\mathrm{A}(10)$ & 2 & 20 \\
\hline $\mathrm{B}(6)$ & 5 & 30 \\
\hline $\mathrm{C}(2)$ & 7 & 14 \\
\hline $\mathrm{R}(0)$ & 6 & 0 \\
\hline Total & 20 & 64 \\
\hline & Average & $(64 / 20)=3.20$ \\
\hline
\end{tabular}

The main findings from the evaluation include the following:

- Of the 22 institutions that completed EPs, average quality scores (FTE weighted) ranged from 3.96 (University of Auckland) to 0.00 (Bethlehem Institute of Education).

- Not surprisingly, the university sector dominated the table. After Auckland came Canterbury (3.83), Victoria (3.39), Otago (3.23) and 
Waikato (2.98). Auckland University of Technology, which recently received university status, obtained a score of 0.77 .

- Across all institutions, the percentage of staff gaining each grade (to the nearest whole number) were: $6 \%$ (A grade); $23 \%$ (B grade); $31 \%$ ( $\mathrm{C}$ grade); and 40\% (R grade). These are fte-weighted values. The peer review panels provided lower percentages in each of the $\mathrm{A}, \mathrm{B}$ and $\mathrm{C}$ grades compared to the internal evaluations provided by institutions themselves. The internal percentages were: $12 \%$ (A grade); 27\% (B grade); 34\% (C grade); and 27\% (D grade). Despite these differences, less than $1 \%$ of internal grades were altered by more than one category, indicating, at least in terms of staff ranking, a high degree of consistency (reliability) in the grading process.

- In respect of subject evaluations, highest average quality scores were obtained for philosophy (4.74), anthropology and archeology (4.55), earth sciences (4.38), ecology, evolution and behaviour (4.18) and biomedical (4.14). Lowest values were obtained by nursing (0.34), design (0.54), education (1.02) and sport and exercise science (1.15). However, these figures conceal important considerations. For example, schools of education that do not at the present time include pre-service teacher education as a major function (e.g., Auckland and Victoria) obtained scores similar to the norms for other subjects.

The last point shows the difficulty in creating "league" tables between institutions without considering other important information which can help make sense of the data.

Research degree completions: The top five institutions for Masters and $\mathrm{PhD}$ completions (respectively) were: Auckland (263/107); Massey (280/68); Otago (190/117); Canterbury (153/85); and Victoria (157/49).

External research income: The external research income of institutions showed very strong effects due to classification (universities accounted for most of the income), subject (the two institutions conducting medical research obtained significantly higher income) and the size of the institution. The top institutions were all universities: Auckland (\$70m); Otago (\$53m); Massey (\$24m); Canterbury (\$14m); and Victoria $(\$ 12 \mathrm{~m})$.
PBRF funding apportionment: Based on the weighting formula given earlier in this paper $(60: 25: 15$ respectively for the three components) and other transformations (described in chapter 8 of TEC, 2004), the major "winners" are again traditional universities: Otago $(+\$ 1.81 \mathrm{~m})$ Auckland $(+\$ 1.59 \mathrm{~m})$; Canterbury $(+\$ 0.38 \mathrm{~m})$; Massey $(+\$ 0.37 \mathrm{~m})$; and Waikato $(+\$ 0.32 \mathrm{~m})$. These figures represent the net impact of PBRF on research funding for 2004.

\section{Issue 1: Impact on teaching}

A critical concern of many academics is that the PBRF will impact negatively on the quality of teaching provided by tertiary institutions - staff time will be directed to research at the expense of maintaining or enhancing quality of teaching. John Hinchcliff (recently retired Vice-Chancellor of Auckland University of Technology) argues that while the PBRF has been a useful first step in rewarding institutions for the quality of their activities, the emphasis should be on the broader concept of "learning" of which "research" is one, albeit major, component (Hinchcliff, 2004). He criticises commentators who incorrectly said that the evaluation will show which departments or schools would be the "top" in their field in the country. He argues that the reward system should be extended to cover the broader student experience and include, in addition to research, outstanding teaching and commitment of universities to their student base. Indicators should include items such as class size, student access to resources, employment success, innovative curricula and other evidence of teaching quality. Of interest here is a text on university education by Bowden and Marton (1999) who argue the case for reconceptualising the modern day university from the notion of a University of Teaching and Research to a University of Learning. The shift to a focus on "learning" isimportant because it recognises that knowledge formation takes place at two levels - the individual level as students come to understand the content of the courses they study, and at the collective level through research where "... human knowledge in its entirety is also widened and humanity learns" (p. 4). The importance of this conception for the present paper is that it affirms Hinchcliff's position by recognising that students, academics, institutions and the community are all involved in the learning process - they are, in fact, all "learners" from the activities of a university. The intention of TEC to conduct in the near future an "evaluation of teaching" exercise is an 
important balance to the system. Whether the TEC is able to embrace the broader concept of learning as proposed by Bowden and Marton is something that will be become clearer when its teaching evaluation model is outlined.

\section{Issue 2: Methodological and procedural concerns}

A number of methodological and procedural concerns have been raised about the PBRF, although, as will be pointed out, not all of these are justified. Concerns have focused on: procedural problems related to the introduction of the system; the criteria for the " $\mathrm{R}$ " category and its meaning; and the validity and reliability of the process. Each of these is addressed in turn.

Procedural problems: As mentioned earlier, because the design was still being finalised at the time TEIs were implementing the PBRF in their institutions, there was uncertainty about what was required and a sense that the rules were constantly being changed. For those engaged in the internal evaluation of their colleagues' portfolios at Victoria University, there was some concern that not everyone had presented a picture that did justice to their achievements. This problem was exacerbated by the tight time frame under which institutions had to operate and the fact that at the critical time for producing portfolios (June to August), staff were heavily involved in examining, marking, course preparation and teaching. Some staff simply did not have the time to respond to suggestions to enhance their portfolio. Clearly, many of these problems will be overcome by the next PBRF round, but there is an important message here for TEC in respect of its plans for an evaluation of teaching quality: do not implement the process until it is fully designed, and allow institutions and their staff reasonable time within which to respond.

The " $R$ " category: Possibly the most challenged aspect of the PBRF process within TEIs has been the interpretation of the category labelled " $\mathrm{R}$ ". Initially this category was given the description "research inactive", although the PBRF report (TEC, 2004) distances itself from this description. Unfortunately, the label has stuck, causing considerable anger amongst new academic staff who had not yet had the time to produce a sufficient number of publications to meet the " $\mathrm{C}$ " category criteria. Included in this group were people whose main research activity during the PBRF period (1997-2002) was the undertaking and completion of a PhD. Such people could hardly be called "research inactive". It should be noted that the PBRF moderation panel has in fact recommended that an additional category should be included to cover new researchers who are active but have not yet had the opportunity to build a substantial portfolio. They also recommend that the completion of a PhD in the prescribed time period should qualify a tertiary teacher for a PBRF score of " 3 " in the next round (Gerritsen, 2004a).

The validity and reliability of the data: Validity and reliability are the two fundamental concepts underpinning measurement of the kind undertaken for the PBRF. Validity focuses on the notion of "fitness for purpose"; the basic idea is that the scores obtained should be based on assessment of the "things" that are genuinely important, and that the consequences of the process (including the side effects) are beneficial, or at least not harmful. Reliability focuses on the notion of accuracy; that whatever the components of the system are, the measurements represent accurate or consistent judgements of how people or organisations performed. Aspects of validity and reliability have already been noted: the interpretation of the " $\mathrm{R}$ " category and the categorisation of new researchers as " $R$ " are examples which question validity. The procedural problems noted earlier represent threats to reliability in respect of those staff who were affected. One could also argue that the final scores for TEIs and subjects, which are reported to two decimal places, create a false sense of precision about the findings. However, despite these particular issues, it is the view of the writers that the system goes some distance towards satisfying both notions, validity and reliability. This is evident in:

- the inclusion of university and other stakeholder expertise in developing a New Zealand relevant system, and not just following a model developed overseas;

- the recognition of the wide-ranging nature of factors that contribute to research excellence, the relevance of the components of the system, the interpretation of what constitutes quality research specific to different subject areas, and the significance given to the impact (not just quantity) of research outputs;

- the development of a comprehensive system of recording and evaluating performance, including the use of internal and external evaluation processes, the appointment of subject experts to 
evaluation panels, the preparation of comprehensive criteria to enable panels to make consistent judgements, and the moderation of the judgements made by different panels to ensure consistency across the system.

While challenges can be made to particular features of the system, as has been done in this paper, there is a high degree of transparency in its make-up, and a clear trail of events and processes which enable an audit or review of the system to be made. This is illustrated, for example, in the work of the moderation panel which considered the particular indicators of quality for different disciplines before requiring any reconsiderations to be made of portfolios. It reached the conclusion that the engineering, technology and architecture panel had been more generous than other panels in its initial evaluation of portfolios. This resulted in a reconsideration of portfolios at the $\mathrm{A} / \mathrm{B}$ and $\mathrm{B} / \mathrm{C}$ boundaries (Gerritsen, 2004b). The point to be made here is that all quality assurance systems should be transparent and open to scrutiny. As the moderation example illustrates, the design and operation of the PBRF conform to these criteria. It then becomes the task of those who challenge the process to make clear, with sound reasons, the structural and operational changes that should be made to improve the system.

One caveat to this analysis of validity and reliability is needed, relating to the long-term impact of the PBRF. The discussion of the policy earlier in this paper highlighted some possible consequences: the merger of non-university institutions; increased competition amongst institutions; appointment policies that give greater emphasis to research than teaching; and the creation of a two-tiered academic staffing system in universities. The important point to be made is that the success of an institution depends on the capabilities of its staff and the commitment of the institution to its human resources. The PBRF has the capacity to change significantly the basis upon which an institution regards its various activities and values the staff who perform different roles. In respect of this capacity to cause change, there is no evidence to suggest that institutions (collectively), communities, or the nation itself will be better off because of the PBRF. Furthermore, the PBRF system has been devised in such a way that there will always be financial winners and losers; the impact of this alone has not been modelled formally. It has simply been regarded as something that institutions will have to cope with through adjustments to their activities so that they remain buoyant. There are clearly significant human resource implications arising from the PBRF, and many unknowns, and how all of this will eventually shake down is still open to considerable speculation.

\section{Issue 3: Funding of the PBRF}

The final issue to be raised in this paper concerns the devolved costs to participating TEIs in the PBRF process. Clearly some TEIs have benefited from the exercise, in the form of funding additional to what they would have received under the former efts-based system. However, what have not been counted are the actual costs to TEIs of undertaking the process. For example, Victoria University will receive approximately $\$ 202,000$ more in funding under the new regime than it received under the old system, but its costs in undertaking the exercise far exceed this reward. Overall, Victoria will receive $\$ 1.57 \mathrm{~m}$ from the PBRF fund for 2004, but its costs for the exercise, including staff time in preparing portfolios, are estimated to have been $\$ 1.64 \mathrm{~m}$. The University of Auckland identified its costs "conservatively" to be $\$ 400,000$. However, these costs do not include the staff time of the managers involved or of the 1411 academics who submitted portfolios (NZPA, 2004, May 31). It is hard to imagine that the overall costs for Auckland would not have exceeded those of Victoria. To illustrate the amount of staff time involved, two of the writers of this paper spent over 40 hours each in preparing their portfolios and in acting as internal evaluators of the EPs of colleagues. The third writer worked almost full-time on the PBRF for several months in her management role within the University's research office. While it is likely that the costs for subsequent exercises will not exceed those for the first round, a full cost-benefit analysis is important if the PBRF is to be properly evaluated for its contribution to advancing New Zealand's tertiary education system. The question to be asked is whether the benefits of the PBRF, in terms of greater research productivity and quality nationwide, outweigh the diversion of funding within institutions (and TEC itself) into managing the process.

\section{Conclusion}

This article has examined the first cycle of the PBRF exercise. It has looked at the policy, along with the design and the operation of the system. It has included a reflection on one institution's response to the system, including its strategy of incorporating a formative dimension 
to the system. The paper has also commented on some of the issues that have arisen from the system. The general conclusion reached by the writers is that the system has been designed carefully and includes many positive features which reflect well on the validity and reliability of the information provided. However, the system has also created significant workload and stress for staff in institutions, and raises concerns about the overall value of the exercise when consideration is given to the human resource implications and the costs to institutions in diverting funds into administering the process.

\section{References}

Bowden, J., \& Marton, F. (2001). The University of Learning: Beyond quality and competence in higher education. London: Kogan Page.

Gerritsen, J. (2004a, May 5-11). New researcher grade recommended. Education Review, p. 4.

Gerritsen, J. (2004b, May 5-11). Consistency between PBRF panels defended. Education Review, p. 3.

Hinchcliff, J. (2004, March 23). Learning the key, not just research. New Zealand Herald, p. A13.

Maharey, S. (2002). Tertiary reform update: A new landscape for tertiary education. Wellington: Transition Tertiary Education Commission.

New Zealand Press Association (2004, May 31). Ranking cost angers varsities. The Dominion Post, p. A3.

New Zealand Vice-Chancellors' Committee (2003, December). Newsletter, No. 69.

PBRF Working Group. (2002). A Performance-Based Research Fund for New Zealand: A discussion document for stakeholders. Wellington: Ministry of Education.

Tertiary Education Advisory Commission (TEAC). (2000). Shaping a Shared Vision. Initial report. Wellington: TEAC.

Tertiary Education Advisory Commission. (2001). Shaping the Funding Framework. Fourth Report. Wellington: TEAC.

Tertiary Education Commission (TEC). (2003). Performance-Based Research Fund: A guide for 2003. Wellington: TEC.

Tertiary Education Commission. (2004). Performance-Based Research Fund, evaluating research excellence: The 2003 assessment. Wellington: TEC.
Transition Tertiary Education Commission \& Ministry of Education. (2002). Investing in excellence: The report of the Performance-Based Research Fund working group. Wellington.

\section{The authors}

Cedric Hall is Professor of Education at Victoria University of Wellington. His teaching and research interests include: education and training; curriculum, learning and teaching; assessment and evaluation; quality assurance in higher education; and education policy.

Kay Morris Matthews is currently Head of School, School of Education, Victoria University of Wellington. She is an educational historian with a special interest in girl's and women's education, and has published in the area of Maori education, educational policy and administration. Kay teaches historical perspectives on educational policy and supervises postgraduate students across the School of Education.

Theresa Sawicka is the Manager, Research Office at Victoria University of Wellington, and was the project Manager for the PBRF evaluation. She is a social anthropologist with a special interest in Polish migration and the experience of the second generation. She continues to supervise post-graduate students in the School of Social and Cultural Studies. 